\title{
Social Entrepreneurship in the Practice of Deliberation and Dialogue
}

Roger A. Lohmann

West Virginia University, roger.lohmann@mail.wvu.edu

Follow this and additional works at: https://researchrepository.wvu.edu/faculty_publications

Part of the Interpersonal and Small Group Communication Commons, Models and Methods

Commons, Nonprofit Administration and Management Commons, Organizational Communication

Commons, $\underline{\text { Public Affairs Commons, and the Social Influence and Political Communication }}$

Commons

\section{Digital Commons Citation}

Lohmann, Roger A., "Social Entrepreneurship in the Practice of Deliberation and Dialogue" (2008). Faculty Scholarship. 798.

https://researchrepository.wvu.edu/faculty_publications/798

This Article is brought to you for free and open access by The Research Repository @ WVU. It has been accepted for inclusion in Faculty Scholarship by an authorized administrator of The Research Repository@ WVU. For more information, please contact ian.harmon@mail.wvu.edu. 


\title{
Social Entrepreneurship in The Practice of Deliberation and Dialogue
}

\author{
Roger A. Lohmann \\ West Virginia University
}

Earlier in this volume, Jon Van Til reviews the major foundational activities in the emergence of public deliberation and sustained dialogue as distinctive approaches to public talk. His focus is on the efforts of a number of social change agents using a variety of distinct approaches. In important respects, public deliberation and sustained dialogue are two of a much larger ensemble of approaches collaborating, competing, and sometimes conflicting with one another for public attention and the scarce resources necessary to make public talk and peaceful co-existence among groups more real. Over the recent decades since peacemaking and citizen participation arrived on the scene, philosophers, notably Jürgen Habermas (1984) and others have detailed more deeply than ever before the pragmatic social and communicative, or conversational basis of democratic political institutions something Harold Saunders (2005) adeptly phrases "politics as relationship".

At the same time, guided typically by their own insights and intuitions of these systematic scholarly soundings, and their own sometimes profound pracademic understandings, several generations of community practitioners have in their own noisy, boisterous, bumptious ways gone about establishing a mind-bendingly diverse web of claims, calls for action, coalitions, organizations, networks, and programs. Some of these represent genuine breakthroughs and innovations; others merely clever twists on wording and effective marketing.

Regardless, the underlying insight is solid and profound: Genuine public conversation is not spontaneous, random, nor - in an era of deep and abiding institutional commitments to 'democracy' as a name for politics controlled by huge, well-heeled corporate interest groups - well supported. Hence, most individuals, groups or communities interested in acting upon their interest in advancing public talk face a relatively daunting range of limited and narrow options. But many also face the challenges of making public talk happen with a drive, enthusiasm, and ingenuity that can be truly awe-inspiring to observe. In the practice of public talk, as in social service, community development and numerous other fields, the quest for resources and public support for these and other, similar efforts generally came to be known as

\footnotetext{
1 This is an author's preprint, a revised and edited version of which is published later as Chapter 23, Lohmann \& Van Til (2011).
} 
"grantsmanship". ${ }^{2}$ It was called this for the very good, practical reason that in the period from 1965-1980 that I have elsewhere termed "the age of grants" it most typically took the form of pursuit of government or foundation grants. (Lohmann \& Lohmann, 2002) Whereas in the distant European or colonial American past, these social entrepreneurs might have sought out individual wealthy patrons for support, in contemporary society, institutional grants most often do the trick.

One tempting notion can be dismissed. Talk is not, in this case, cheap. It is highly unlikely that greater collective commitment to deliberation and dialogue in most communities will come about without significant infusions of additional resources. It is unlikely that deliberation and dialogue will come into widespread use simply by being good ideas. Deliberations and dialogue sessions need to be planned, organized, staged, conducted and taught by skilled and knowledgeable practitioners and teachers, and guided by informed and targeted research if they are to be more widely adopted. These things cost money and time. Citizen-to-citizen deliberations of the type suggested by advocates of public deliberation, and dialogue to address long term public conflicts like those suggested by advocates of sustained dialogue will never be cost-free endeavors. At a minimum, the public and strategic conversations involved unfold through time, and in the process take up time in people's lives; time they cannot spend in other pursuits as a consequence.

In the pracademic domain suggested by the title of this book, where scholarly and practice interests truly meet and converge, grantsmanship the pursuit of grant-funding for programs and services - is but one (important) way of supporting public talk; one type of change agentry, or as it is increasingly known in our highly commercial civilization, social entrepreneurship. The change agents who write grants and in myriad other ways stimulate public support for deliberation and dialogue are, truly, social entrepreneurs. Likewise, the committees, (mostly nonprofit) organizations, networks, and communities they foster and sustain are important contemporary forms of social enterprise. Social enterprise, entrepreneurship and entrepreneurs are very popular terms at the moment and mean many different things to different users of these terms. So, what do we mean by these terms?

An entrepreneur has been defined in the for-profit literature as the catalytic agent who sets into motion new enterprises with new combinations of production and exchange (Carter and Cannon, 1992; Collins \& Moore, 1970). Although the concept of 'entrepreneurship' is closely linked with the for-profit sector and may seem out of place in the nonprofit world, it is not. Both kinds of enterprises are

\footnotetext{
2 The term itself entered the language in the anonymous manner of most new words, but one of the early adopters, Norman Kiritz, was also one of the pioneering social entrepreneurs when he founded the Grantsmanship Center in 1972. He died this year and deserves to be remembered by all who read this chapter.
} 
the result of the entrepreneu r's innovation, leadership, imagination, effort, and ability. Using definitions from the for-profit literature, we define entrepreneurs in either sector as self-directed, innovative leaders who start an enterprise, with new combinations of production and exchange to either promote goods and services for private profit or to promote a social cause. (Handy and Ranade, 2006)

Such terms have seldom been employed in discussions of deliberation and dialogue and probably don't occur together anywhere else in this book, in part because most authors are focused on the main event - the conversations themselves - and not the sometimes-complex backstage logistics that made those conversations possible. ${ }^{3}$ Thus, some clarification may be necessary before the relevance of this chapter to the enterprise that is this book may be clear.

The Ashoka Foundation, for example, says "The job of a social entrepreneur is to recognize when a part of society is stuck and to provide new ways to get it unstuck."

(http://www.ashoka.org/fellows/social entrepreneur.cfm) Stuck is a term that characterizes very nicely many conflict situations where sustained dialogue might apply. Stuck is also a term that Mansbridge (1990), Barber (1988) and others might be comfortable with to describe their critiques of democracy in contemporary society.

But, how are we to get a divided community or democracy unstuck? Bill Drayton, CEO, chair and founder of Ashoka, a global nonprofit organization devoted to developing the profession of social entrepreneurship, and thus himself a social entrepreneur in our sense, offers this rather fulsome metaphor: "Social entrepreneurs are not content just to give a fish or teach how to fish. They will not rest until they have revolutionized the fishing industry." (http://www.skollfoundation.org/aboutsocialentrepreneurship/index.asp)

Is such talk of social entrepreneurship something completely and entirely new? Probably not, but then that isn't an especially damning criticism: Social change theory has an extensive history of periodically putting old wine into new bottles; a history that probably can be traced most of the way back to Ancient Greek philosophers. What is most noteworthy about the social entrepreneurial model today is the remarkable number of potential entrepreneur/change agent/reformers who are energized by this notion. Also of interest is that many of them and their organizations are new to the game!

\footnotetext{
3 One main theoretical fault line here is between the "rationalist/materialist" economic perspective of the economists and the "romantic/interactionist" of the softer social sciences. Another major theoretical fault line emerges ultimately from the Scottish moralists' "common sense" perspective and the European "romantic" - initially German and French - reaction against Adam Smith and the "materialistic" classical economists.
} 
At a time when other competing models of gradual or incremental change appear to have largely run their course, advancing democracy through social enterprises devoted to "selling democracy" may be one of the most viable options available.

The twin concepts of social entrepreneurs (persons) and social enterprises (organizations) thus offer a fairly neat and tidy way to begin to deconstruct the rapidly growing institutional framework of organizations and networks of persons devoting substantial amounts of time, energy and resources to advancing the cause of more deliberative forms of democracy.

In general terms I wish to suggest first that the challenge of advancing the practice of public talk in the contemporary United States is a social entrepreneurial challenge for individuals, groups, organizations and communities. ${ }^{4}$ At any given point in time, delivering even a brief program of deliberation on a widespread basis or, a program of sustained dialogue over an extended period requires acquiring and utilizing significant resources and assets; in contemporary jargon, of building and utilizing human, social, financial and intellectual capital for production. The obvious nature of this connection is deeply embedded in much of the current talk about social capital: the role of networks of trust and relationships that form the matrix within which meaningful economic relations can be established.

In the new global democratic order, interest in deliberation and dialogue as manifestations of civil society is genuinely international, and not simply in the example of "shuttle diplomacy" in which Harold Saunders played a critical role. The participants in this book alone have been involved in or studied religious, ethnic, gender, class and other "across difference" deliberation and dialogue efforts in more than a dozen countries on at least four continents.

These efforts are usually carried out by social entrepreneurs who share a familiar profile: Studies of nonprofit entrepreneurs have identified several characteristics such as willingness to take risks, self-directedness, leadership, innovation, and a focus on what they can do for others. (Pilz, 1995, quoted in Handy, Ranade \& Kassam, 2006) And these, in general, are the same resource expectations of deliberation and dialogue efforts, as an email message, sent over the NCDD Discussion list on January 30, 2006 suggests:

We started an annual deliberative and dialogue forum in 2002 to proffer peace(solutions) for (to) Nigeria's oil/gas exploration communities and the exploration companies and need funding support/ collaboration in implementing this programme across the Niger Delta, all year round ....

$4 \quad$ The basic topic of this chapter emerged in conversations with Harold Saunders and others over the challenge of locating resources to carry out programs of sustained dialogue. 
Practitioners and academics alike may see the development of deliberation and dialogue in terms of enhanced communication, as many of the chapters in this book show. They might also be viewed in idealistic terms as reflecting the eventual triumph of noble or lofty ideals over ignorance, error and unreason. Some of us - perhaps guided by a profound feminist theory insight - might see this as the triumph of voice over silence. Yet, sooner or later, the underlying economic reality of resource limits is bound to set in; the reality that introducing greater measures of deliberative democracy into contemporary post-industrial society and more widespread recognition of the importance of relationships in resolving conflict both requires strategic deployment of substantial resources. And, it isn't always clear where those resources will come from.

Even with an abundance of volunteers, the ideals of deliberation and dialogue can make relatively little headway in the general polity and advance beyond the status of noble but impractical ideas without significant investments of time, energy, and other resources. Thus, a fundamental concern for anyone working in these efforts must be with where these resources are to come from. As Handy, Ranade and Kassam (2006) note:

Entrepreneurs, whether producing goods and services under the aegis of for-profit institutions or nonprofit organizations face similar challenges: identifying opportunities, promoting innovative ideas, implementing ideas into viable enterprises, mobilizing resources, and undertaking risks inherent in starting a new project. (Handy, Ranade \& Kassam, 2006)

A pracademic union of awareness of the theoretical concerns that have interested a great many legal and political authors over recent decades with the urgency of organizing a particular set of conversations in a particular place at a particular time is likely also to involve an approach to social change very much like that described by contemporary social entrepreneurial thinkers: Advancing deliberation and dialogue becomes a matter of "selling" the recognition that there is a problem with interest-group democracy or with community violence to potential sponsors, and then selling distinct, identifiable branded efforts at deliberation and dialogue as legitimate solutions to this problem.

The problem of sustained dialogue currently involves a particularly challenging sales and marketing task: Even in normal circumstances, there is the challenge of convincing the parties to a conflict that talking is better than fighting. In a post-911 world with our national government officially committed to imperialism, the notion of conflict resolution by any means other than armed intervention and violence seems to many to be an anachronism: why talk with your enemy? Isn't it better (safer, more secure) to brand him a terrorist and kill him? Moreover the entrepreneurial problem is remarkably recursive. Even talking about whether to talk requires access to resources!

In economic terms, there currently appear to be larger numbers of willing sellers for the concept of more widespread deliberation and dialogue, but many fewer buyers willing to invest resources. There may be a market, but it has some distinctive characteristics. It 
is suspected of being a largely third-party market in which those who consume the services are not the same as those being asked to pay the bills. While huge numbers of our contemporaries would readily pay $\$ 50$ or more for a concert, sporting event or article of clothing, we suspect that few, if any, would pay a comparable amount to participate in any type of citizenship process. Thus, the market for deliberation and dialogue seems peculiarly skewed. It would appear, for example, that social entrepreneurs willing to organize and conduct deliberation and dialogue events are currently more numerous than either third party buyers of such services or even citizen participants who are the ultimate consumers of such services. It is also plausible, however, that the skew runs along an entirely different diagonal: That merely seeing the need for this kind of effort does not result in personal willingness to make the necessary resource commitments in any of the usual forms - personal consumption expenditures, willingness to pay higher taxes, or voluntary, philanthropic donations. Therefore, grant or donated funds are thought to be so necessary that the more entrepreneurial waters are never tested.

This suggests that the nub of the resource problem for deliberation and dialogue is what in economics is recognized as a problem of cost allocation: Why should people, groups, organizations, foundations, government agencies and others commit scarce resources at their disposal (including their own time) to public deliberation or sustained dialogue when there are so many other legitimate, worthwhile activities for them to invest in $?^{5}$ In this vein, the opportunity cost of deliberation and dialogue is the critically important resource issue facing both public deliberation and sustained dialogue today. It also points to the heart of the entrepreneurial challenge facing the various change agents seeking to promote these activities. While the problem is usually addressed from a narrowly limited 'common sense' perspective (where can we get a grant to do this activity? would people pay to attend that event?), the focus of this chapter is to suggest that there are few simple answers to be found in that direction. Instead, the larger problem should be recognized for what it is using concepts like social entrepreneurship and social capital: an issue of human, political and social capital acquisition and market formation. From an entrepreneurial standpoint, this involves several related questions, mostly involving a careful analysis of what it is that can be gained and given up:

- Who are the potential 'stakeholders' with something important to gain or lose from a deliberation or dialogue? (including such important gains as a deeper sense of citizenship or peace for participants in a conflict, and losses of power, face or wealth)?

- Can any of the anticipated losers be redefined into winners?

- What are the actual costs of participation for participants? (Not just in dollar outlays, but in the "opportunity costs" of other opportunities given up, etc.

- What are the opportunity costs for funders? (Why, in particular, should a donor or foundation faced with many different requests fund a deliberation or dialogue effort?)

\footnotetext{
${ }^{5}$ It may not be clear to the reader, but cost in this sense is focused on the future and planned or projected events, as opposed to the conventional accounting usage, which adopts a historical perspective on past events. Sources often use the term 'opportunity cost' to refer to this usage and the term 'cost outlay' to refer to the latter.
} 
- What are the products/packages (services or benefits) offered by deliberation or dialogue?

- Are those products distinctive and do they possess clear brand identity? (In the ways, for example, that Head Start, Habitat for Humanity, the Red Cross and United Way do?)

- Are those products, services and benefits being packaged in ways that genuinely appeal to potential participants?

An important current research agenda resides in where, and how, and why, such choices will be made. The direction of resources to this set of concerns, whether in the form of grants, donations, fees and user payments, volunteer time or some other medium will depend on the answers to those questions.

The opportunity cost of sustained dialogue can be measured fairly precisely - and in some cases, quite dramatically - in terms of the cost of conflict and accompanying violence deferred as a consequence of dialogue. This leads to a familiar cost-benefit formulation: The likelihood of communities incurring losses due to property destruction, lives lost, work and business disrupted, and expenditures for police, fire and military services. These and other, quite real, consequences will be considerably higher in some instances and at some times than at others. Thus, the cost of sustained dialogue in any given community will be variable while the costs of putting on the program will remain relatively more constant. Thus, the perceived benefit will rise and fall accordingly.

Of particular note is the likelihood that the cost-benefit ratio of sustained dialogue will be greatest - that is, the benefits will be proportionately greater relative to the costs incurred - in the period when conflict is high but before the outbreak of violence. It probably costs no more to initiate a sustained dialogue when the likelihood of violence is high than at other times, but the payoffs will almost certainly be more immediate and obvious. Focusing on a cost-benefit model allows us to see more clearly the dilemma this poses: If the point of the term "sustained" in the Saunders model of sustained dialogue is that there are advantages to dialogue in non-crisis periods - indeed, to prevent whenever possible the rise of such crises - why does it appear to so many to be less costly to wait until a crisis arises before acting? There is another research agenda in answering that question.

The opportunity cost of public deliberation is somewhat more complex to conceptualize in entrepreneurial terms. There are additional factors to consider, such as the opportunity cost of leadership? Why would a community leader enter into a difficult and more costly sustained dialogue effort, for example, when it could potentially raise difficult or embarrassing questions? A public relations campaign to 'spin' the issue will almost certainly be less costly. Such logic can easily lead to a high probability that public officials will oppose (tacitly at least) such efforts. What is the alternative against which the deliberation of citizens is to be measured or compared? Silence? Is this an issue of voice? Of public representation of differing points of view? Of simple enactment of rites of citizenship? A great deal of current thinking appears to center principally around two related themes: declines in civic participation and associated losses of social capital. 
For significant numbers of potentially active citizens and community leaders, the opportunity cost of participation in deliberation and dialogue must currently be thought to be too high, as reflected by relatively widespread indifference and unwillingness to participate in civic life. Addressing this issue as a concern of opportunity cost offers another way to bring resource concerns directly up against the very social, political, and cultural issues addressed by public deliberation and dialogue, such as the reasons for declining civic participation, and the unwillingness to confront intractable racial, cultural and other conflicts. How bad, for example, must a community conflict become before large numbers of people will see engaging it as less costly than continuing to ignore it? (At what point will the cost of inaction begin to exceed the cost of doing nothing?)

Treating issues of participation in deliberation and dialogue as issues of social enterprise in this sense has not been at all common; at least in my reading of the literature. Doing so allows an important connection between the vital missions of such efforts and the means to realize those missions. It also provides a fundamental and farreaching framework for direct comparisons of the various models of deliberation and dialogue. What are the costs (including opportunity costs) and benefits of each? Comparing the costs and benefits of these models in even roughly comparable circumstances would be one way to make useful observations on the relative contributions of each in public life. The challenge, however, is that enthusiasts for any community project seldom wish to have their enthusiasm dampened by asking this kind of question. In most instances, we all would prefer to ask the familiar rhetorical questions: Why don't 'they' (non-participants) understand what we are trying to do? Why don't they get it? Why can't we reach them and get them involved? The general hypothetical answer to all of these questions offered by of the cost perspective is: Because the costs they see of participating outweigh any benefits they perceive.

The challenge of practice in this area, then, becomes one of how to meet, or better yet lower, those costs or increase the perceived benefits. In deliberation and dialogue this typically involves comparing incomparables (e.g. dollar outlays with the advantages of citizenship or conflict prevented or deferred) and it must be said we really aren't very good at that. One challenge for social entrepreneurs in this area that is directly linked to the prospect of future success of these efforts is to find better ways of making such comparisons.

Fitting a social entrepreneurial model to deliberation and dialogue is no idle conjecture: The contemporary practice of deliberation and dialogue is already evolving within a social entrepreneurial environment. The dominant forms of contemporary D\&D practice frequently unfold within nonprofit grassroots and community organizations, utilizing processes and actors in widely recognized modern forms of social change induced through voluntary action. Most typically, they must at some point 'pay for themselves' whether through donations or grant revenues or some other resource stream. The incidental evidence offered by participation in the NCDD discussion list suggests that a substantial portion of current activity takes place in these nonprofit community venues and with the state, national and regional consultants who service them.

Typically, community-level social entrepreneurs in this area seek, as the quotation above suggests, to package, promote and disseminate programs or products in a marketplace of ideas dominated largely by nonprofit organizations. For at least the past 
century, the familiar matra of such efforts has been a problem-focused one. In efforts to advance these and other good ideas, the problems of encouraging greater civic involvement and addressing major social conflicts are being packaged, marketed and "sold" by numerous local, regional, national and international social entrepreneurs based in nonprofit organizations. Much like Professor Harold Hill, practitioners in this area promote the notion that there is "trouble, my friends, right here in River City." Declining or inadequate civic participation and the threat of violence, it should be noted generally offer general purpose problem-focused takes on a great many things. It is worth considering the advantages that might arise from adopting more positive outlook, perhaps akin to the 'wellness' approaches in health care or the emerging 'strengths perspective' in social work. The problem of prospective violence and threat, for example, is indeed a daunting one in any community, but also, frequently a powerful fundraising tool; the entire history of military, police defense and security budgets shows this. On the other hand, as Saunders' model ably attests, we (individuals, groups and communities) have within us the strengths (the resources, or human and social capital, as it were) to confront those prospects and build the necessary relationships - if we can find the resources necessary to do so. David Bornstein uses a popular strengths perspective theme to define: "Social entrepreneurs identify resources where people only see problems." (quoted at http://www.pbs.org/opb/thenewheroes/whatis/ ) This same theme is woven into the entrepreneurial model of the Skoll Foundation which defines a social entrepreneur as "society's change agent; [a] pioneer of innovations that benefit humanity." (http://www.skollfoundation.org/aboutsocialentrepreneurship/index.asp)

There is some evidence to suggest that things are shifting somewhat away from problem-focused approaches and toward 'less negative' empowerment and 'strengths' models in the present. To the extent this is the case, it is reflected in the changing nature of entrepreneurial actions. It remains to be seen how, whether, and under what circumstances, deliberation and dialogue campaigns can be sold on strengths, rather than problem-centered models. Even so, public deliberation and conflict resolution are currently not recognized marketable consumer goods for which people would be willing to purchase admission as they might tickets to an athletic event, artistic exhibition, medical appointment, movie or day at a theme park. Thus, financing deliberation or dialogue activities through participant sales seems only remotely possible at present. There are, in other words, no existing product markets for D\&D.

Nonprofit social enterprise of this sort conforms to a characteristic form of what I call the "dual dyad" of voluntary action (Figure 1), that would involve two distinct, but related, sales campaigns for deliberation and dialogue efforts. Moore (2000) refers to this as managing "upstream" (donors) and "downstream" (clients and services). Rather than the conventional interaction of buyers and sellers found in markets, grant and donorsupported situations generally involve two separate initiatives by nonprofits (or trustees), with two distinct groups: donors, able to commit the necessary resources, and beneficiaries, interested in gaining from the deliberation or dialogue experience. First, there is the challenge of selling the concepts of deliberation and dialogue to patrons: foundations, government agencies and other financial agents to gain the necessary 
resources. ${ }^{6}$ Secondly, using the resources acquired in this way to market participation in the deliberative or dialogical experience to assorted bodies of citizens, or parties to a conflict. In the nonprofit form of such entrepreneurship, foundations, government agencies, donors and other resource providers must first be sold on the idea of the need for a set of conversations and be willing to put up the enabling resources. Only then, are the various idea brokers of deliberation and dialogue positioned for the second sale encouraging widespread "free" (or subsidized, low-cost) participation in actual deliberation and dialogue sessions.

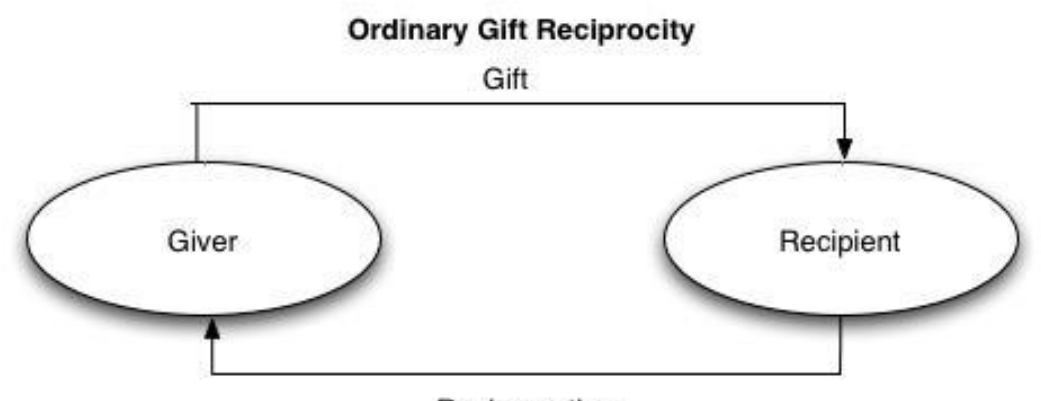

Reciprocation

(Gift, Acknowledgement, Tribute, etc.)

Dual Dyad Reciprocity in Benefactory

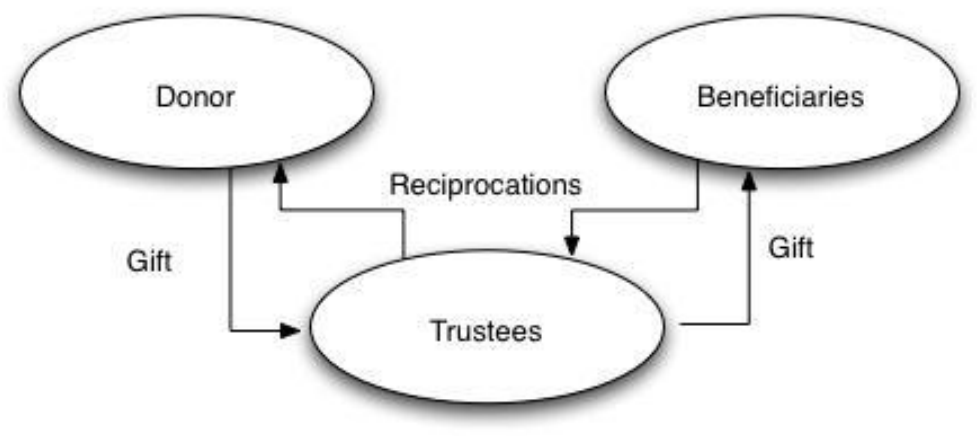

Focusing on the entrepreneurial aspects of deliberation and dialogue also raises the possibility of direct, market activities: product development and testing, direct sales to

$6 \quad$ The argument for the dual dyad is laid out in part in R.A. and N. Lohmann, Social Administration, Columbia University Press: New York, 2002. In brief, the point is the necessary yoking of two separate and distinct transactions: one to raise funds; the other to deliver the goods, in this case, deliberation or dialogue sessions. 
willing consumers and the like. A number of regional and national consultants have already discovered this. For most community advocates in nonprofit settings, however, direct marketing of deliberation and dialogue 'products' may appear to be too daunting a challenge, with substantial risks and only limited prospects of returns on their investment. All in all, the dual dyad of nonprofit action within the traditional third sector is widely seen as the most feasible available alternative.

The field of D\&D may currently be in a stage where nonprofit activity is a necessary form of research and development: How could anyone be an intelligent consumer of D\&D products (be willing to invest an amount equal to the cost of participation), when none of us is really sure, yet, what those products are? Who knew 50 years ago what day care centers and intermediate care facilities for the elderly were? Today, one can approach purchases of such services with some semblance of knowledge, information on quality and the like. This is not yet true with deliberation and dialogue and there is, of course, no assurance it ever will be.

The issues involved here are complex: If each resident of Belfast, Northern Ireland could for the price of 5 pounds sterling (or 500 or 5,000) engage in a sustained dialogue process that would guarantee a permanent end of the troubles, would they be willing to do so? If each American could, for the price of $\$ 200$ purchase a share in a more directly deliberative democracy would they? Both questions are moot because no one can make such assurances.

In the case of public deliberation, of course, there are additional strong reasons why the experience of citizenship should not be packaged and sold like a day at Disneyland; to do so undermines the reality and immediacy of the actual experience in subtle but profound ways. By contrast, limited markets have already emerged for some types of private, and even public conflict resolution (such as marriage counseling, and generic forms of mediation services) in which consumers are willing to pay for the costs of the intervention effort. However, applications of sustained dialogue on a broader societal scale with problems like ethnic, religious or racial conflict is not something that is easily reduced to a marketable commodity. The public goods nature of peace and the "externalities" of the issue are simply too overwhelming to make that very likely.

Thus, as a practical matter social problem entrepreneurship in deliberation and dialogue typically involves pursuit of social entrepreneurial strategies like grantwriting, fundraising and development, promotion and sale of assorted books, pamphlets, and other promotional materials, fee-based consulting, conference presentations and workshops, creation of nonprofit organizations and/or networks and other tactics to promote particular ideas, 'models', programs or other packaged approaches to solving particular social problems. Such activities may not be entrepreneurial in the ordinary business sense; profit maximization should almost certain take a back seat to service. Indeed, the devices and tactics of entrepreneurial activity are usually seen as necessary evils; what must be done to advance agendas that are largely civic, humanitarian and professional in nature. But whether or not we see them as evil, they are certainly necessary.

Entrepreneurial activity along these lines has also been working to fashion a secondary 'marketplace of ideas' in which a large and growing number of social entrepreneurs interested in selling their ideas about deliberation and dialogue through 
books, workshops, "how-to" guidebooks, consulting contracts and other commodities are also in pursuit of the limited range of financial and institutional support in hopes of attracting the attention of much larger audiences of idea-consumers whose acceptance would signal the rise of more robust forms of citizen democracy. Apparently, one cannot yet make a living selling public deliberation directly to the public, but one can make a living at conflict resolution and all of the assorted training and support activities designed to enable others to do so. (As I wrote this, a discussion was ongoing on the NCDD discussion list on this very question: How c an one make a living doing D\&D?

The dual dyad faced by nonprofit deliberation and dialogue entrepreneurs also conforms in several respects and is related to a dual-dyad model of public opinion formation, with entrepreneurs in the role of "opinion leaders". ${ }^{7}$ Much contemporary deliberation and dialogue entrepreneurship is directed at forming, capturing or converting foundations, public agencies, professional associations, publishers and other potential opinion makers. ${ }^{8}$ These assorted platforms and programs are then to serve as "bully pulpits" for reaching out to large audiences of citizens with messages of participation and active citizenship. Perhaps the strongest reason for such entrepreneurial thinking is to be found in the temporary nature of this strategy: Foundations, in general, are well known for the gossamer nature of their support. Prior experience predicts that those that can be convinced to fund deliberation and dialogue projects will see their support as short-term underwriting of innovation, demonstration and change efforts and not capital formation; the expectation will be that long-term operational funds will come from elsewhere. (Where, exactly, is seldom their concern.) At the same time, growing out of the experiences with "community action" in the late 1960s, politicians and government agencies are unlikely to provide much support: Active, participating citizens, particularly those with grievances, are notoriously unruly, and inclined to all manner of unpredictable behavior.

However, the key danger for all in this entrepreneurial model is not its antiestablishmentarianism. It is the risk of commodification of civic action and problemsolving into vendible products and the associated goal and mission displacements that would imply. When we reach the point that a particular nonprofit becomes more interested in sales of its handbook or the "gate proceeds" of attendance at its events than in their impact upon community governance, commodification has set in.

The risk inherent in necessary resource seeking is of allowing the legitimate need for resources to turn active citizenship and social problem solving into packaged experiences, after the manner perhaps of some forms of eco-tourism. How could we generate the resources necessary to carry out programs encouraging more active citizenship, and yet

\footnotetext{
7 In important respects, this process resembles the Lazarsfeld, et. al. "two-step flow of communication" (Lazarsfeld, Berelson and Gaudet, 1948; Berelson, Lazarsfeld and McPhee, 1985 ) in which public opinion is formed as various "opinion makers" receive and interpret news and information and pass their opinions on to others who in turn adopt the views they hear from the opinion makers.

${ }^{8}$ Most notable in this regard, perhaps, are the Kettering Foundation's ongoing commitment to brands (one might even call it a related product line) including the National Issues Forum, Public Choice and products like public deliberation, and the Jefferson Center's trademarked Citizen Juries. Community Design Teams, Question Mapping, Appreciative Inquiry, and many other emerging brands are also noted.
} 
prevent the inversion of means and ends, so that maintenance of deliberation and dialogue enterprises and the production and sale of D\&D products - books, pamphlets, programs, speeches, conferences, consulting services - do not become ends in themselves? How do we avoid the 'silver haired legislature' experience, where senior citizens can have a day filled with all of the thrills, but none of the risks and dangers of being an elected official, gaining a 'new insight into state government' and yet go home largely unchanged by the experience? (http://www.shls.org/index.html)

Most deliberation and dialogue entrepreneurs appear aware to varying degrees of these dangers, although whether awareness will be sufficient to avoid them is not clear. The concept of social entrepreneurship has been approached in many different ways by its various advocates and in the process has attracted many subtleties of meaning. For some, the term social entrepreneurship connotes little more than a fashionable cliché of the present age roughly comparable to similarly vacuous labels of the recent past like "social change" and "change agent" (which in turn largely replaced $19^{\text {th }}$ century terms like revolution, reform, revolutionary and reformer). In skilled hands, the entrepreneurial model has been used to bring together images of social innovation and resultant changes with connotations of organizational leadership and the use of sophisticated management tools including product development, marketing, public relations and image management, and the kind of resource acquisition or "capital formation" necessary to make meaningful changes at the level of a culture as self-aware and ironic and a society as organizationally complex as the ones we live with.

\section{Conclusion}

Focusing on deliberation and dialogue as problems of social entrepreneurship calls attention to an inherent challenge of leadership for national, international, regional and community leaders of D\&D efforts: where to obtain the necessary resources to carry out - to capitalize, as it were -organized programs of deliberation and dialogue. The problem is inherently complex in part because there is currently nothing resembling an economics of conversation, even strategic conversation, and in a fundamental sense that's what deliberation and dialogue are. The challenge of the social entrepreneur, in brief, is to sell that which is not for sale; to cover the costs of activities, which have no price.

It is additionally complex because of the difficulty of drawing any hard and fast connections between these conversations and events that don't happen as a result. According to the theory, when dialogue occurs, conflict is resolved, violence is prevented or minimized; when deliberation among citizens takes place, engagement happens and democracy works better. This is where formulating the resource issue as a problem of opportunity cost and cost-benefit consideration becomes valuable: Who can say what the cost of not engaging in sustained dialogue or public deliberation may be? As a matter of fact, we can. Using an opportunity cost approach, these costs can be 
measured in terms of the increased risks of violence and of citizen apathy and non-participation. And as these risks are clarified and estimated, the rationale for resources committed to deliberation and dialogue is strengthened accordingly.

Two conclusions follow from this: First, in the short run, with the absence of hard and fast evidence establishing the costs and benefits of deliberation and dialogue, one of the tasks for leaders in the deliberation and dialogue movement will continue to rhetorically make this connection. This is a major sub-text running, for example, through the published work of David Matthews and Harold Saunders, and several of the chapters in this book. In the longer run, the focus on social entrepreneurship must be a major part of the case for greater research emphasis and scholarly attention to deliberation and dialogue, particularly from the vantage point of the costs of not engaging and the benefits of doing so. 


\section{References}

Habermas, J. (1984). The theory of communicative action. Boston: Beacon Press.

Lohmann, R. A., \& Lohmann, N. (2002). Social administration. New York: Columbia University Press.

Saunders, H. H. (2005). Dialogue as a Relational Act: Sorely Needed in South Asia. International Studies Review, 7, 314-316.

Lohmann, R. A., \& Van, T., Jon. (2011). Resolving community conflicts and problems : public deliberation and sustained dialogue. New York: Columbia University Press.

Mansbridge, J. J. (1990). Beyond Self Interest. Chicago: University of Chicago Press.

Barber, B. R. (1988). The Conquest of Politics: Liberal Philosophy in Democratic Times. Princeton NJ: Princeton University Press.

Handy, F., Ranade, B., \& Kassam, M. (2007). To profit or not to profit:

Women entrepreneurs in India. Nonprofit Management \& Leadership, 17(4), 383-402.

Berelson, B., Lazarsfeld, P. F., \& McPhee, W. N. (1986). Voting : a study of opinion formation in a presidential campaign (Midway reprint ed. ed.).

Chicago: University of Chicago Press.

Lazarsfeld, P. F., Berelson, B., \& Gaudet, H. (1948). The people's choice; how the voter makes up his mind in a presidential campaign ([2nd ed.] ed.). New York: Columbia Univ. Press. 